[0212-7199 (2008) 25: 3; pp 141-148] ANALES DE MEDICINA INTERNA Copyright (C) 2008 ARAN EDICIONES, S.L.

An. Med. InTERna (Madrid) Vol. 25, N. ${ }^{\circ}$ 3, pp. 141-148, 2008

\title{
Uveítis. Un reto para el internista
}

\author{
L. M. CALVO HERNÁNDEZ, R. M. BAUTISTA SALINAS, R. CERVERA SEGURA ${ }^{1}$ \\ M. SUÁREZ CABRERA
}

Servicio de Medicina Interna. Hospital Universitario Insular de Gran Canaria. ${ }^{1}$ Unidad de Enfermedades Autoinmunes Sistémicos. Hospital Clínic. Barcelona

UVEITIS. A CHALLENGE FOR INTERNIST

Calvo Hernández LM, Bautista Salinas RM, Cervera Segura R, Suárez Cabrera M. Uveítis. Un reto para el internista. An Med Interna (Madrid) 2008; 25: 141-148.

\section{INTRODUCCIÓN}

Las uveítis son un grupo heterogéneo de entidades clínicas, de muy diversas causas, que tienen en común la inflamación intraocular. Pueden ser la manifestación de una enfermedad generalizada ya establecida, ser un proceso limitado al globo ocular, o incluso ser el primer signo clínico de una entidad que se desarrollará con el tiempo. Por ello, el internista, con ayuda del examen oftalmológico, intentará buscar manifestaciones extraoculares específicas, para así solicitar las pruebas complementarias oportunas según su hipótesis diagnóstica.

La uveítis es todo proceso inflamatorio que afecta al tracto uveal. Cuando la inflamación está limitada a una región concreta se utilizan términos como iritis, iridociclitis, coroiditis, coriorretinitis, retinocoroiditis y pars planitis, según la zona afecta. No obstante, en muchas ocasiones sólo es posible precisar la existencia de una uveítis anterior, intermedia o posterior.

En la patogenia de la uveítis intervienen factores genéticos, ambientales e inmunológicos, destacando en estos últimos el papel de los linfocitos $\mathrm{T}$ y de los antígenos de clase II del complejo mayor de histocompatibilidad.

La incidencia de uveítis oscila en los países desarrollados entre 15-17 casos por 100.000 habitantes según las series, constituyendo un 10-15\% de nuevos casos de ceguera $(1,2)$. Se suele presentar en la cuarta década de la vida, aunque puede afectar a cualquier edad.

Las uveítis pueden estar desencadenadas por agentes exógenos (traumatismos, postcirugía, etc.) o ser de tipo endógeno (limitadas al ojo o en el contexto de una enfermedad sistémica). El amplio abanico de causas de las uveítis endógenas hace en ocasiones difícil el diagnóstico y que el tratamiento sea en la mayoría de los casos empírico, motivo por el cual se convierte en un auténtico reto (3).

\section{ETIOLOGÍA}

Las causas de uveítis son múltiples. Nos limitaremos a las uveítis endógenas. Podemos agruparlas en: síndromes limitados al ojo, causas infecciosas, síndromes de enmascaramiento y enfermedades sistémicas (4).

- Síndromes limitados al ojo.

- Uveítis idiopáticas: es el grupo más frecuente y la mayoría son de localización anterior. El 50\% de las uveítis anteriores no presentan otra enfermedad sistémica asociada (5). Un primer episodio de uveítis anterior sin otra sintomatología no requiere estudios ulteriores.

- Uveítis anterior HLA B 27 sin artropatía: son uveítis agudas de localización anterior con antígeno HLA B27 positivo que se presenta como entidad clínica aislada sin que se objetiven síntomas o signos de artropatía (6).

- Síndromes oftalmológicos específicos: se diagnostican en la mayoría de los casos únicamente con el examen oftalmológico y no requieren estudios ulteriores (7-9). Los principales síndromes oftálmicos específicos son: pars planitis, ciclitis heterocrómica de Fuch's, coroidopatía de Birdshot, necrosis aguda retiniana, neurorretinitis de Leber, coroidopatía serpinginosa, fibrosis subretiniana, oftalmia simpática y traumatismos.

- Causas infecciosas.

Las infecciones son causas frecuentes de uveítis y pueden producirse tanto por bacterias, virus, hongos como por parásitos (Tabla I). El diagnóstico precoz es importante ya que el

Trabajo aceptado: 30 de octubre de 2007

Correspondencia: Luz Marina Calvo Hernández.e-mail: lucicalvoh@hotmail.com I Rosa María Bautista Salinas.e-mail: rosa_bautista@yahoo.es 
TABLA I

\begin{tabular}{lccc}
\multicolumn{4}{c}{ TABLA I } \\
& CAUSAS INFECCIOSAS DE LA UVEÍTIS & \\
\hline Bacteriana/Espiroquetas & Virales & Hongos & Parásitos \\
\hline Tuberculosis & Citomegalovirus & Candidiasis & Toxoplasmosis \\
Sífilis & Virus de Epstein Barr & Pneumocystis jiroveci & Toxocariasis \\
Enfermedad de Lyme & Virus herpes simple & Aspergilosis & Acanthamoeba \\
Enfermedad de Whipple & Virus de inmunodeficiencia humana & Cystercercosis \\
Enfermedad por arañazosis de gato & Virus herpes zoster & Coccidiomicosis & Onchocerciasis \\
Micobacterias atípicas & Rubéola & Cryptococcosis & \\
Brucelosis & Parotiditis & Histoplasmosis & Esporotricosis \\
Lepra & & & \\
Leptospirosis & & & \\
Propionibacterium & & &
\end{tabular}

tratamiento varía dependiendo del microorganismo. En algunas ocasiones tienen un patrón específico como la infección por Citomegalovirus (CMV) o la candidiasis.

- La toxoplasmosis es relativamente frecuente en pacientes inmunocompetentes, siendo de alto riesgo las personas inmunocomprometidas. En la mayoría de los casos se trata de una reactivación de una infección adquirida previamente o bien, de una infección congénita $(10,11)$. Produce lesiones características con necrosis de la retina y en etapas avanzadas lesiones coriorretinianas pigmentadas en sacabocados que cicatrizan y se acompañan de vitritis densa (12).

- La tuberculosis (TBC) puede afectar tanto al segmento anterior como posterior de la úvea. Suele ser de curso crónico. Hoy en día es una causa poco frecuente, sobre todo en los países con una baja incidencia de esta enfermedad. En España, la prevalencia oscila entre 0,4-5,9\% según distintos estudios, con una línea claramente descendente en los últimos años. Las manifestaciones oculares más frecuentes incluyen iritis granulomatosa o no granulomatosa y los tubérculos coroideos. El diagnóstico se establece por lesiones típicas oculares, prueba de tuberculina positiva, radiografía de tórax compatible y aislamiento de micobacterias en esputo o bien mediante biopsia ocular, la cual establece el diagnóstico definitivo (13-15).

- El virus herpes simple suele producir queratitis dendrítica asociada a uveítis anterior. Con menos frecuencia afecta al segmento posterior con coriorretinitis y necrosis retiniana aguda (16-18).

- Síndromes de enmascaramiento.

Comprenden un grupo de entidades clínicas que producen signos inflamatorios que se pueden confundir con una uveítis endógena. Reviste especial importancia debido a la posibilidad de asociarse a tumores malignos. La neoplasia que más frecuentemente se presenta como uveítis es el linfoma, típicamente el de células B. Se deben sospechar ante uveítis crónicas, refractarias al tratamiento con esteroides y en las inflamaciones posteriores bilaterales en mayores de 45 años $(19,20)$. Los principales son:

- Síndromes de enmascaramiento asociados a tumor maligno: linfoma intraocular, melanoma, leucemias, retinoblastoma y metástasis.

- Síndromes de enmascaramiento no asociados a tumor maligno: cuerpo extraño, desprendimiento de retina y distrofia retiniana.

- Enfermedades sistémicas no infecciosas.
Entre las enfermedades sistémicas no infecciosas destacan:

- Patologías reumáticas asociadas al complejo de histocompatibilidad B 27 como la espondilitis anquilosante, la artritis reactiva, la artritis crónica juvenil (ACJ) y la artritis psoriásica (21-25). Otro grupo importante lo constituyen la artritis reumatoide y la enfermedad de Still.

- Las enfermedades autoinmunes son causas frecuentes de uveítis $(26,27)$, destacando entre ellas la enfermedad de Behçet (28), la sarcoidosis (29), el lupus eritematoso sistémica (30), la granulomatosis de Wegener $(31,32)$, el síndrome de Sjögren, la poliarteritis nodosa, el síndrome antifosfolipídico y otras vasculitis sistémicas (33).

- Finalmente existe un grupo misceláneo de procesos que pueden presentar en cualquier momento de su curso una uveítis, como por ejemplo la enfermedad inflamatoria intestinal (34-36) (EII), la esclerosis múltiple $(37,38)$, la enfermedad de Vogt-Koyanagi-Harada (38) (VKH), la enfermedad celíaca, la amiloidosis, el síndrome TINU $(39,40)$ (nefritis tubulointersticial y uveitis), la enfermedad de Kawasaki $(41,42)$, y la enfermedad de Whipple $(43,44)$ entre otras.

La aparición de un proceso uveítico en el contexto de una enfermedad sistémica que lo justifique debe ser asumido en el contexto clínico de dicha enfermedad, debiéndose siempre excluir la sífilis y la tuberculosis. En este último caso además de por su diagnóstico adecuado es importante su exclusión por el tratamiento immunosupresor que el paciente va a recibir.

1. La espondilitis anquilosante (EA) es una espondiloartropatía que afecta el esqueleto axial y se presenta típicamente en varones entre 20 y 40 años con HLA B 27 positivo. La manifestación ocular más frecuente es la iridociclitis aguda no granulomatosa, unilateral y recidivante. La uveítis ocurre en el $20-40 \%$ de los pacientes y puede preceder a la afectación articular. Asimismo, el 30\% de los varones con uveítis anterior aguda desarrollará EA $(21,25)$.

2. La enfermedad de Behçet es un proceso inflamatorio, crónico, caracterizado por aftosis recurrente orales y múltiples manifestaciones como aftosis genital, afectación ocular, cutánea, neurológica, vascular o articular. Afecta fundamentalmente a jóvenes entre 20 y 30 años y se asocia típicamente a la presencia del antígeno HLA B51. La afectación ocular ocurre entre el 25 y el $75 \%$ de los pacientes con enfermedad de Behçet y en muchos casos puede ser grave. En el 10\% constituye la primera manifestación. La afectación más frecuente es la uveítis anterior y en casos graves puede cursar con material en cámara anterior o 
hipopion. Aunque la afectación ocular suele ser unilateral, acaba típicamente siendo bilateral y episódica. También puede cursar como uveítis posterior o coriorretinitis y en ocasiones puede existir panuveítis. Otras manifestaciones oculares son la conjuntivitis, neuritis óptica, vasculitis retiniana, oclusión vascular, episcleritis y la escleritis (28).

3. La sarcoidosis es una enfermedad granulomatosa de origen desconocido que cursa en forma de brotes e incluye afectación pulmonar con adenopatías hiliares, hepatoesplenomegalia, afectación cutánea, articular, glándulas lagrimales y sistema nervioso central. La afectación ocular ocurre en el 20$40 \%$ de los casos, siendo casi en el $20 \%$ la primera manifestación. La sarcoidosis puede afectar la conjuntiva, la espisclera y rara vez, la órbita y la esclera. La iridocliclitis es la complicación más frecuente; puede ser aguda o crónica. La aguda, generalmente unilateral, afecta típicamente a jóvenes con sarcoidosis aguda. La iridociclitis crónica, con frecuencia bilateral, es más común que la forma aguda. El segmento posterior está afectado en el $25 \%$ de los casos y generalmente se asocia a la uveítis anterior. Suele deberse a penetración granulomatosa de los vasos de la coroides y de la retina $(45,46)$.

-Las causas de uveítis según su localización se exponen en la tabla II.

\section{CLASIFICACIÓN}

Debido a la heterogeneidad de las uveítis, se han propuesto varias clasificaciones (47). Clásicamente las más utilizadas son las clasificaciones anatómica, clínica, patológica y etiológica. Recientemente, los miembros del International Workshop of uveitis han propuesto una nueva clasificación basada en la localización, el curso clínico, el grado de inflamación y la evolución de la actividad de las uveítis (48).

- Clasificación anatómica.

Es la más utilizada. Se basa en la localización primaria del segmento ocular que se considera origen del proceso inflamatorio $(48,49)$ (Tabla III). Se distinguen así cuatro tipos de uveítis:

- Uveítis anterior: es la forma más frecuente (60\%).

\begin{tabular}{|c|c|c|}
\hline \multicolumn{3}{|c|}{ TABLA III } \\
\hline \multicolumn{3}{|c|}{$\begin{array}{c}\text { CLASIFICACIÓN ANATÓMICA DE LAS UVEÍTIS SEGÚN THE } \\
\text { STANDARIZATION OF UVEITIS NOMENCLATURE (SUN) } \\
\text { WORKING GROUP (48) }\end{array}$} \\
\hline Tipo & $\begin{array}{c}\text { Localización primaria } \\
\text { de la inflamación }\end{array}$ & Formas \\
\hline Uveítis anterior & Cámara anterior & $\begin{array}{l}\text { Iritis } \\
\text { Iridociclitis } \\
\text { Ciclitis anterior }\end{array}$ \\
\hline Uveítis intermedia & Vitreo & $\begin{array}{l}\text { Pars planitis } \\
\text { Ciclitis posterior } \\
\text { Hialitis }\end{array}$ \\
\hline Uveítis posterior & Retina o coroides & $\begin{array}{l}\text { Coroiditis focal, } \\
\text { multifocal o difusa } \\
\text { Coriorretinitis } \\
\text { Retinocoroiditis } \\
\text { Retinitis } \\
\text { Neurorretinitis }\end{array}$ \\
\hline Panuveítis & nterior, vítreo y retina o & \\
\hline
\end{tabular}

TABLA II

CAUSAS DE UVEÍTIS SEGÚN SU LOCALIZACIÓN

\begin{tabular}{|c|c|}
\hline Localización & Entidades clínicas \\
\hline Uveítis anterior aguda & $\begin{array}{l}\text { Idiopática, HLA B27 sin artropatía, espondiloartropatía } \\
\text { seronegativa, espondilitis anquilosante, síndrome de Reiter } \\
\text { enfermedad inflamatoria intestinal (EII), psoriasis, sarcoido- } \\
\text { sis, artritis crónica juvenil (ACJ), síndrome de Vogt-Koya- } \\
\text { nagi-Harada (VKH) e infecciones: lúes, Virus Herpes Sim- } \\
\text { ple, Virus Herpes Zoster, enfermedad de Lyme y parásitos }\end{array}$ \\
\hline Uveítis anterior crónica & $\begin{array}{l}\text { Idiopática, espondiloartropatía seronegativa, ACJ, lúes, sín- } \\
\text { drome de Sjögren, síndrome de Reiter, enfermedad de } \\
\text { Behçet, sarcoidosis }\end{array}$ \\
\hline Uveítis intermedia & $\begin{array}{l}\text { Idiopática (pars planitis), enfermedad de Beçhet, sarcoido- } \\
\text { sis, enfermedad de Lyme, esclerosis múltiple y síndrome de } \\
\text { Sjögren }\end{array}$ \\
\hline Coriorretinitis unilateral & $\begin{array}{l}\text { Toxoplasmosis, virus Herpes, toxocariosis, sarcoidosis, lúes, } \\
\text { tuberculosis }\end{array}$ \\
\hline Coriorretinitis bilateral & $\begin{array}{l}\text { Enfermedad de Behçet, toxoplasma, coroidopatía de Birds- } \\
\text { hot, sarcoidosis, síndrome de VKH }\end{array}$ \\
\hline Vasculitis retiniana & $\begin{array}{l}\text { Enfermedad de Behçet, Lupus Eritematoso Sistémico, vas- } \\
\text { culitis sistémicas, síndrome antifosfolipídico, tuberculosis, } \\
\text { lúes, sarcoidosis, Ell }\end{array}$ \\
\hline
\end{tabular}

Afecta al iris, cuerpo ciliar o a ambos. Suele ser aguda y autolimitada (Fig. 1).

- Uveítis intermedia: representa entre el 5 y el $13 \%$ aproximadamente de las uveítis. La localización primaria de la inflamación es el cuerpo vítreo. Se denomina pars planitis cuando se trata de uveítis intermedia de causa idiopática, la más frecuente $(>50 \%)$; y cuando se asocia a infecciones o a enfermedades sistémicas se usa el término uveítis intermedia.

- Uveítis posterior: representa el $15 \%$ de las uveítis. Puede afectar a la coroides, retina y la porción posterior del cuerpo vítreo. Clásicamente se ha considerado la vasculitis retiniana dentro de las uveítis posteriores.

- Panuveítis: afecta a toda la úvea y constituye el $20 \%$ de todas las uveítis.

- Clasificación clínica: según forma de inicio, duración y curso de la uveítis.

- Según el comienzo, éste puede ser súbito o insidioso.

- Según la duración, ésta puede ser limitada ( $\leq 3$ meses) o persistente ( $>3$ meses).

- Grado de inflamación y complicaciones. Las uveítis también se clasifican según la presencia de células y proteínas ("fla$r e^{\text {") }}$ en la cámara anterior. Así, se pueden distinguir 6 grados:

- Grado 0, cuando existe < 1 Célula en la Cámara Anterior (CCA) y no existen proteínas.

- Grado 0,5+, cuando existen entre 1-5 CCA.

- Grado $1+$, cuando existen entre 6-15 CCA, con ligera presencia de proteínas.

- Grado 2+, cuando existen entre 16-25 CCA, con moderada presencia de proteínas (exudado proteináceo claro, si bien persisten los detalles iridianos).

- Grado 3+, cuando existen entre 26-50 CCA, con marcada presencia de proteínas (no se distinguen los detalles iridianos).

- Grado 4+, cuando existen > $50 \mathrm{CCA}$, con intensa presencia de proteínas (depósito de fibrina).

Asimismo también es importante especificar la presencia o ausencia de hipopion. 


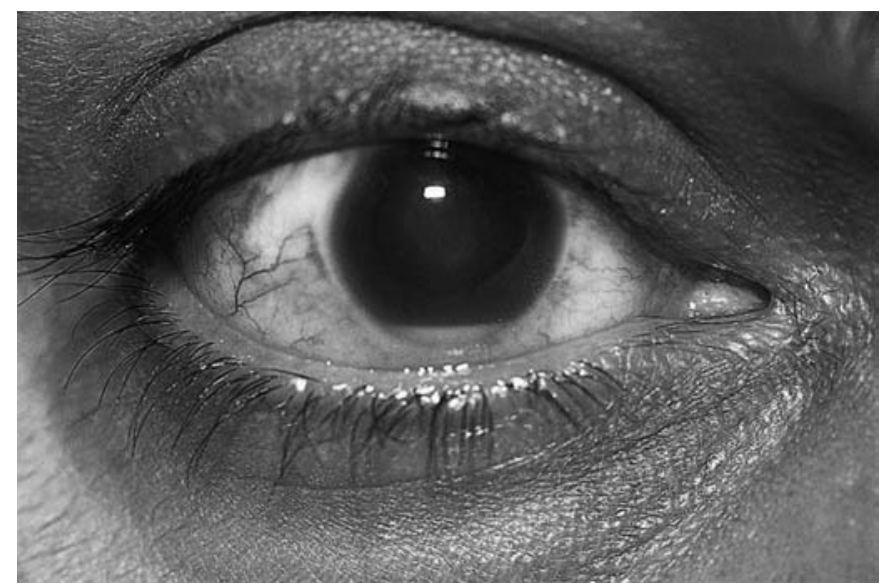

Fig. 1. Uveítis anterior.

- Grado de actividad. Según la evolución de la actividad, encontramos:

- Inactiva: sin células en cámara anterior.

- Empeoramiento de actividad: aumento en 2 grados el nivel de inflamación (células en cámara anterior, turbidez vítrea) o cambio del grado $3+$ al $4+$.

- Mejoría de actividad: disminución de 2 grados el nivel de inflamación o descenso al grado 0.

- Remisión de actividad: inactividad de la enfermedad 3 meses después de la suspensión del tratamiento de la uveítis.

\section{MANIFESTACIONES CLÍNICAS}

Los síntomas de la uveítis dependen de la zona de la úvea afectada.

-Uveítis anterior.

- Uveítis anterior aguda: los principales síntomas son fotofobia, dolor, enrojecimiento, disminución variable de la agudeza visual y lagrimeo. En la exploración oftalmológica se objetiva hiperemia iridiana y ciliar periquerática, miosis y exudación en la cámara anterior (fenómeno Tyndall). Otros signos pueden ser precipitados queráticos y sinequias.

- Uveítis anterior crónica: los síntomas son menos evidentes que en la aguda. Suele haber mayor turbidez visual.

-Uveítis intermedia.

La sintomatología es más inespecífica. El síntoma de presentación suele ser las miodesopsias aunque alguna vez puede comenzar con pérdida de visión central debido al edema macular cistoide crónico. En la mayoría de los casos la parte externa del ojo no está alterada, sin signos inflamatorios. La cámara anterior presenta escasas o ninguna célula y en el fondo de ojo hay ausencia de lesión inflamatoria focal. El signo más característico es la vitritis donde se objetiva infiltrado celular prominente y agregados de células en la parte inferior denominado "bolas de nieve o algodón".

-Uveítis posterior.

Los dos síntomas de las uveítis posteriores son las miodesopsias y la disminución de la agudeza visual. Puede cursar sin participación del segmento anterior. En el fondo de ojo puede haber un grado variable de turbidez vítrea, exudados focales en coroides y retina, vasculitis o desprendimiento exudativo de la retina.

\section{APROXIMACIÓN DIAGNÓSTICA}

Como ocurre siempre que se haga una correcta praxis médica, se debe intentar averiguar la causa de la uveítis, puesto que de ello depende el tratamiento y el pronóstico. La dificultad radica en el elevado número de síndromes conocidos y su elevada variabilidad semiológica, lo que obliga en muchas ocasiones a aplicar tratamientos empíricos. No obstante, hay que tener en cuenta que en más del $50 \%$ de los casos no se llega al diagnóstico de ninguna entidad y es preciso etiquetar el cuadro de uveítis idiopática. Distintos estudios han demostrado que el uso indiscriminado de pruebas complementarias no aumenta la rentabilidad diagnóstica. Se deben utilizar protocolos individualizados y éstos deben incluir las características en la exploración oftalmológica (localización anatómica, comienzo, duración, curso, grado de inflamación y complicaciones y grado de actividad) ya que orientarán a posibles enfermedades sistémicas (Tabla IV).

A todos los pacientes se les debe realizar una historia clínica con una anamnesis por aparatos completa, una exploración física incluyendo la exploración del esqueleto axial y unas pruebas complementarias básicas. Posteriormente y de forma individualizada según el tipo de uveítis, los datos de la anamnesis y los resultados de las pruebas realizadas se puede establecer un listado de posibilidades diagnósticas en base a las cuáles se practicarán otras pruebas más específicas (50-53).

En la historia clínica se hará mención especial a la edad, sexo, antecedentes familiares, personales y epidemiológicos, hábitos sexuales y hábitos tóxicos, toma de fármacos (54-56) como bifosfonatos $(57,58)$, metipranolol tópico, topiramato, rifabutina (59), sulfonamidas, inmunorrecuperación tras triple terapia antirretroviral (HAART, highly active antiretroviral therapy) (60), etc.

En las pruebas complementarias básicas se incluirán siempre el hemograma, VSG, coagulación, bioquímica de sangre completa y proteinograma; bioquímica de orina; serología luética y prueba de la tuberculina (Mantoux); electrocardiograma, radiografía de tórax posteroanterior y lateral; y una autoinmunidad básica que incluya la determinación anticuerpos antinucleares (ANA), factor reumatoideo, HLA B 27 y B5.

Según la localización anatómica de la uveitis se realizarán junto a las pruebas complementarias básicas, unas pruebas específicas (Tabla V), u otras, si se estima oportuno en función del resultado de la anamnesis y de las pruebas anteriores:

-Tipaje HLA. Se asocia a distintas entidades estando presente el HLA B27 en cerca del $90 \%$ de los pacientes con espondilitis anquilosante, $80 \%$ en pacientes con síndrome de Reiter, $75 \%$ con artritis psoriásica (75\%) y 50\% com enfermedad inflamatoria intestinal. Existen otras frecuentes asociaciones, como son el HLA B 5/51 con la enfermedad de Behçet, el HLA B29 con la coroidopatía de Birdshot, el HLA A 1 con la sarcoidosis sarcoidosis, el HLA A 11 con la oftalmía simpática y el HLA B 53 con el síndrome de Vogt-Koyanagi-Harada y la crisis granulocítica.

- Tomografía computarizada (TC) torácica y gammagrafía con galio pueden ser útiles pára el diagnóstico de sarcoidosis.

-TC craneal y/o Resonancia Magnética si existe clínica neurológica asociada o sospecha de lesiones ocupantes de espacio (p. ej. linfoma).

- Ecografía ocular para tumores intraoculares y síndromes de enmascaramiento. 
TABLA IV

PATRONES OFTALMOLÓGICOS

\begin{tabular}{|c|c|}
\hline Entidad & Patrón oftalmológico \\
\hline $\begin{array}{l}\text { - Idiopática } \\
\text { - Espondiloartropatía } \\
\text { - Artritis crónica juvenil } \\
\text { - Sarcoidosis } \\
\text { - Enfermedad de Behçet } \\
\text { - Lupus eritematoso sistémico } \\
\text { - Poliarteritis nodosa } \\
\text { - Enfermedad inflamatoria } \\
\text { - Síndrome de Vogt-Koyanagi-Harada } \\
\text { - Esclerosis múltiple } \\
\text { - Enfermedad de Kawasaki } \\
\text { - Toxoplasmosis } \\
\text { - Whipple } \\
\text { - Tuberculosis } \\
\text { - Enfermedad de Lyme } \\
\text { - Enfermedad por arañazo de gato } \\
\text { - Sífilis } \\
\text { - Endoftalmitis bacteriana }\end{array}$ & $\begin{array}{l}\text { - Uveítis anterior aguda } \\
\text { - Uvétis anterior aguda recurrente } \\
\text { - Uveítis anterior crónica no granulomatosa bilateral } \\
\text { - Iridociclitis aguda granulomatosa. Afectación posterior. Periflebitis } \\
\text { - Uveítis anterior bilateral, recidivante, no granulomatosa. Hipopion estéril } \\
\text { - Vasculitis retiniana } \\
\text { - Vasculitis retiniana multifocal } \\
\text { - Uveítis anterior aguda no granulomatosa, bilateral no intestinal simultánea, brotes, } \\
\text { curso crónico } \\
\text { - Uveítis anterior bilateral crónica granulomatosa. Uveítis posterior con desprendimiento } \\
\text { de retina exudativo } \\
\text { - Pars planitis. Uveítis anterior aguda granulomatosa, bilateral, sinequiante } \\
\text { - Uvéitis anterior y conjuntivitis } \\
\text { - Uveítis anterior granulomatosa o no granulomatosa. Coriorretinitis } \\
\text { - Iridociclitis crónica } \\
\text { - Uveítis anterior crónica granulomatosa. Coroiditis focal } \\
\text { - Uvétis anterior granulomatosa bilateral, vitritis, pars planitis } \\
\text { - Uvé́tis intermedia y posterior. Conjuntivitis } \\
\text { - Iridociclitis aguda granulomatosa o no. Presencia de roseola. Crónica sin tratamiento } \\
\text { - Afectación posterior difusa con vitritis endógena }\end{array}$ \\
\hline
\end{tabular}

TABLA V

PRUEBAS COMPLEMENTARIAS ESPECÍFICAS SEGÚN LA LOCALIZACIÓN ANATÓMICA DE LA UVEÍTIS

\begin{tabular}{ll}
\hline Localización & Pruebas complementarias específicas \\
\hline Uveítis anterior & Serología herpética y radiograffa simple de articulaciones sacroilíacas \\
Uveítis intermedia & Serología Borrelia burgdorferi \\
Uveítis posterior tipo coriorretinitis & Serología: toxoplasrna, toxocara y herpes virus. HLA B 29 \\
Uveítis posterior tipo vasculitis retiniana & ANCA $^{1}$ crioglobulinas, anticuerpos antifosfolipídicos \\
\hline
\end{tabular}

${ }^{1}$ ANCA: anticuerpos anticitoplasrna de neutrófilo.

- Serología intraocular de humor acuoso/vítreo, si fuera necesario.

- Citología, útil en entidades como linfoma intraocular, toxoplasmosis, etc.

- Cultivos de aspirado acuoso o vítreo y PCR (Polymerase Chain Reaction). Especialmente útil para: toxoplasma, tuberculosis, virus herpes, lúes, virus de Epstein Barr, varicela, Thropheryma whipplei, etc.

- Biopsia de tejidos intraoculares, de gran utilidad en el diagnóstico de tumores, sobre todo linfoma intraocular.

- Estudio de autoinmunidad más específico, según la sospecha clínica.

\section{TRATAMIENTO}

El tratamiento apropiado de la uveítis dependerá de la extensión, la gravedad, la presencia de complicaciones, así como de la causa. Cuando se trata de una uveítis de causa infecciosa el tratamiento es el específico de dicha infección. Así, el tratamiento para la toxoplasmosis incluye pirimetamina, sulfadiacina y ácido polínico, junto con corticoides según el grado de inflamación (61). En caso de alta sospecha clínica de tuberculosis, se inicia un tratamiento empírico, el mismo que para otras formas de la enfermedad, siendo de 6 meses en inmunocompetentes y hasta 1 año en inmunodeprimidos (1315). Ante una uveítis anterior por virus herpes simple, el tratamiento es con aciclovir tópico y ciclopléjicos; mientras que cuando existe afectación posterior se suele requerir tratamiento sistémico $(16-18,62)$.

En los casos en los que la uveítis sea parte de una enfermedad sistémica, el grado de actividad de ésta también influirá en la elección del tratamiento. No obstante, en la mayoría de los casos éste suele ser inespecífico, siendo los corticoides el pilar del tratamiento. Cuando no hay respuesta a los corticoides tópicos ni sistémicos y dado que parece que existe una base autoinmune en la lesión ocular, el arsenal terapéutico con inmunosupresores que se utiliza es similar al 
de este grupo de enfermedades $(63,64)$. La elección del mismo se realizará de forma individualizada. Las uveitis en el contexto de la espondilitis anquilosante suelen responder a tratamiento tópico con ciclopléjicos y corticoides. En la enfermedad de Behçet, el tratamiento de la uveítis anterior consiste en primer lugar en la administración de corticoides tópicos, si no hay respuesta se debe administrar prednisona vía oral, y en caso de recidiva se debe iniciar tratamiento con ciclosporina A. El tratamiento de la uveítis posterior en la enfermedad de Behçet, son los esteroides sistémicos y la ciclosporina A; aunque actualmente existen muchos agentes inmunosupresores como la azatioprina, el metrotexate o el micofenolato de mofetilo que se pueden asociar al tratamiento anterior en caso de evolución tórpida; y cada vez existe mayor experiencia y buenos resultados con el infliximab, el cual se ha utilizado en casos de uveitis posteriores y anteriores refractarias, o si la terapeútica previa es mal tolerada. En la sarcoidosis, el tratamiento con corticoides cuando se administra al principio del cuadro es eficaz, aunque las recidivas son frecuentes y el pronóstico a largo plazo es malo. Los nuevos tratamientos, al igual que en la enfermedad de Beçhet, mejoran el pronóstico.

Los principales agentes para el tratamiento de estas entidades clínicas se resumen a continuación: 1) corticoides, 2) inhibidores de calcineurina (ciclosporina A y tracolimus), 3) antimetabólicos (azatioprina, micofenolato de mofetilo y metotrexate), 4) alquilantes (ciclofosfamida y clorambucil) y 5) agentes biológicos como los Anti-TNF.

\section{CORTICOIDES}

-Tópicos: de primera elección. Principalmente en uveítis anteriores agudas.

-Inyección periocular: cuando se necesita mayor efecto en el segmento posterior. Con la preparación depot se consigue una acción prolongada. Indicado en uveítis anterior aguda grave, uveítis intermedia, y como tratamiento adjunto al tópico o sistémico en casos de uveítis anteriores crónicas resistentes y en pacientes mal cumplidores.

-Sistémicos: primer escalón en caso de no respuesta al tratamiento tópico. Dosis de $1 \mathrm{mg} / \mathrm{kg} /$ día durante un mes. Disminuir progresivamente la dosis (en 3 meses aproximadamente) para evitar efectos secundarios.

\section{INHIBIDORES DE CALCINEURINA}

-Ciclosporina A: es un fármaco que produce inmunosupresión selectiva de linfocitos T. Actúa rápidamente y es más efectiva cuando se usa con glucocorticoides. Está indicado como segundo escalón en las uveítis secundarias a enfermedad de Behçet, ACJ, la enfermedad de VKH, coroiditis y panuveitis idiopáticas entre otras. La dosis es de $5-10 \mathrm{mg} / \mathrm{kg} /$ día en dos tomas, durante 3 meses tras respuesta terapeútica y posteriormente iniciar descenso. Tiene efecto dosis dependiente. Es bien tolerada y los principales efectos secundarios son la afectación renal y la hipertensión arterial. Su principal problema es la recidiva tras la suspensión del tratamiento $(65,66)$.

-Tacrolimus: se utiliza en la enfermedad de Behçet y en caso de uveítis posteriores con ausencia de respuesta a la ciclosporina normalmemte (67). Dosis de $0,15 \mathrm{mg} / \mathrm{kg} / \mathrm{día}$. Los efectos secundarios son similares a la ciclosporina, pero hay que tener especial atención con la neurotoxicidad.

\section{ANTIMETABOLITOS}

-Azatioprina: se ha usado clásicamente en el tratamiento de la uveítis, especialmente en enfermedad de Behçet (68), también en la enfermedad de VKH (69), coroiditis serpinginosa (70) y otras vasculitis retinianas. La dosis es de 0,5-2,5 $\mathrm{mg} / \mathrm{kg} / \mathrm{día}$. Las principales complicaciones son la afectación hematológica y la hepática.

-Micofenolato de mofetilo: su uso es cada vez más frecuente con muy buena tolerancia. Varios estudios demuestran buena respuesta y es útil como ahorrador de glucocorticoides $(71,72)$. Es menos efectivo en monoterapia. Se suele emplear en caso de uveitis posteriores refractrias, tras terapia combinada y asociado a ciclosporina. La dosis es de 0,5-2 g/12 horas.

-Metotrexate: indicado en uveítis HLA B27, ACJ, sarcoidosis, artritis psoriásica y otras espondiloartropatías, vasculitis retiniana, enfermedad de Behçet y panuveitis idiopática, entre otras (73). Dosis de 7,5-25 mg/semana, asociado a ácido fólico. Tiene pocos efectos secundarios, consiguiéndose respuesta hasta en el 70\% de los casos.

\section{ALQUILANTES}

-Ciclofosfamida: se ha usado con éxito en pacientes con uveítis refractaria a otros inmunosupresores con severo compromiso de la agudeza visual. Indicada especialmente en vasculitis retiniana. Se puede administrar en forma de bolus intravenoso o vía oral. Los efectos secundarios son la toxicidad gonadal, inmunodepresión y la cistitis hemorrágica (74).

-Clorambucil: se utiliza en caso de no respuesta a otros inmunosupresores. Indicado en la enfermedad de Behçet con afectación del sistema nervioso central (75). Los efectos secundarios son el riesgo de linfoma o leucemia. Se recomienda su uso durante periodos cortos, normalmente no mayores a 6 meses.

\section{BIOLÓGICOS}

-Anti-TNF: son fármacos capaces de inhibir la acción del TNF alfa (76). Existen dos tipos: los receptores solubles (etanercept) y los anticuerpos anti TNF (infliximab y adalimumab).

- Infliximab: fármaco eficaz en pacientes con afectación ocular resistente a corticoides, azatioprina o ciclosporina. Está especialmente indicado en vasculitis retiniana y vitritis (77-80).

- Etanercept: estudios demuestran eficacia en la enfermedad de Behçet, pero no es tan eficaz en las lesiones oculares como el anterior $(81,82)$.

-Anti-receptor IL 2, daclizumab: se une a la subunidad TAC o CD25 del receptor de alta afinidad de IL-2 expresado en los linfocitos T activados y bloquea la unión de IL-2 al receptor y la consiguiente estimulación de la IL-2 de la proliferación y diferenciación de los linfocitos T. Está actualmente en fase I/II para el tratamiento de uveítis no infecciosa intermedia y posterior con buen resultado $(80 \%)(83,84)$. 


\section{Bibliografía}

1. Forrester JV. Uveitis: pathogenesis. Lancet 1991; 338: 1498-501.

2. Suttorp-Schulten MS, Rothova A. The possible impact of uveitis in blindness: a literature survey. Br J Ophtahalmol. 1996; 80: 844-8.

3. Rosenbaum Jt, Nozik RA. Uveitis: Many diseases, one diagnosis. Am J Med. 1985; 79: 545-7.

4. McCannel CA, Holland GN, Helm CJ, Cornell PJ, Winston JV, Rimmer TG. Causes of uveitis in the general practice of ophthalmology. UCLA Community-Based Uveitis Study Group. Am J Ophthalmol 1996; 121: 35-46.

5. Santin M, Badrinas F, Mascaro J, Nolla JM, Pujol O, Roca G, et al. Uveitis: An etiological study of 200 cases following a protocol. Med Clin (Barc) 1991; 96: 641-4.

6. Suhler EB, Martin TM, Rosenbaum JT. HLA-B27-associated uveitis: Overview and current perspectives. Curr Opin Ophthalmol 2003; 14: 378-83.

7. Monnet D, Brezin AP, Holland GN, Yu F, Mahr A, Gordon Lk, et al. Longitudinal cohort study of patients with birdshot chorioretinopathy. I. Baseline clinical characteristics. Am J Ophthalmol 2006; 141: 135-42.

8. LeHoang P, Ozdemir N, Benhamou A, Tabary T, Edelson C, Betuel H, et al. HLA-A29.2 subtype associated with birdshot retinochoroidopathy. Am J Ophthalmol 1992; 113: 33-5.

9. Damico FM, Kiss S, Young LH. Sympathetic ophthalmia. Semin Ophthalmol. 2005; 20: 191-7.

10. Rothova A. Ocular manifestations of toxoplasmosis. Curr Opin Ophthalmol 2003; 14: 384-8.

11. Holland GN. Ocular toxoplasmosis: A global reassessment. Part I: Epidemiology and course of disease. Am J Ophthalmol 2003; 136: 973-88.

12. Holland GN. Ocular toxoplasmosis: a global reassessment. Part II: Disease manifestations and management. Am J Ophthalmol 2004; 137: 1-17.

13. Martín-Armada M, Jiménez Alonso J, Herranz MT, Castro Durán J. Tuberculosis and uveitis. Med Clin (Barc) 1998; 111: 799.

14. Demirci H, Shields CL, Shields JA, Eagle RC Jr. Ocular tuberculosis masquerading as ocular tumors. Surv Ophthalmol. 2004; 49: 78-89.

15. Mehta S, Gilada IS. Ocular tuberculosis in acquired immune deficiency syndrome (AIDS) Ocul Immunol Inflamm 2005; 13: 87-9.

16. Yoser SL, Forster DJ, Rao NA. Systemic viral infections and their retinal and choroidal manifestations. Surv Ophthalmol 1993; 37: 313-53

17. Madhavan HN, Priya K, Biswas J. Current perspectives of herpesviral retinitis and choroiditis. Indian J Pathol Microbiol 2004; 47: 543-68.

18. Guex-Crosier Y, Rochat C, Herbort CP. Necrotizing herpetic retinopathies. A spectrum of herpes virus-induced diseases determined by the immune state of the host. Ocul Immunol Inflamm 1997; 5: 259-65.

19. Park S, Abad S, Tulliez K, Merlat A, Gyan E, Bouscary D, et al. Pseudouveitis. A clue to the diagnosis of primary central nervous System Lymphoma in immunocompetente Patients. Medicine (Baltimore) 2004; 83: 223-32.

20. Whitcup SM, de Smet MD, Rubin BI, Palestine AG, Martin DF, Burnier M Jr, et al. Intraocular lymphoma. Clinical and histopathologic diagnosis. Ophthalmol 1993; 100: 1399-406.

21. Sampaio-Barros PD, Conde RA, Bonfiglioli R, Bertolo MB, Samara AM. Characterization and outcome of uveitis in 350 patients with spondyloarthropathies. Rheumatol Int 2006; 26: 1143-6.

22. Monet D, Breban M, Hudry C, Dougados M, Brezin AP. Ophthalmic findings and frequency of extraocular manifestations in patients with HLA-B27 uveitis: A study of 175 cases. Ophthalmol 2004; 111: 802-9.

23. Kump LI, Castaneda RA, Androudi SN, Reed GF, Foster CS. Visual outcomes in children with juvenile idiopathic arthritis-associated uveitis. Ophthalmol 2006; 113: 1874-7.

24. Chen CS, Roberton D, Hammerton ME. Juvenile arthritis-associated uveitis: Visual outcomes and prognosis. Can J Ophthalmol 2004; 39: 614-20.

25. Martin TM, Smith JR, Rosenbaum JT. Anterior uveitis: Current concepts of pathogenesis and interactions with the spondyloarthropathies. Curr Opin Rheumatol 2002; 14: 337-41.

26. Pras E, Neuman R, Zandman-Godbard G, Levy Y, Assia E, Shoenfeld $\mathrm{Y}$ et al. Intraocular inflammation in autoimmune diseases. Semin Arthritis Rheum. 2004; 34: 602-9.

27. Carbone J, Sarmiento E, Micheloud D, Rodríguez-Mahou M, Rodríguez-Molina JJ, Cobo R, et al. Systemic autoimmune disease in patients with uveitis. Arch Soc Esp Oftalmol 2006; 81: 193-8.

28. Bonfioli AA, Orefice F. Behcet's disease. Semin Ophthalmol 2005; 20 : 199-206.
29. Adán A., Baget M, de Llobet JM, Segura A, Marieges MT, CasaroliMarano R. Uveítis como manifestación inicial de sarcoidosis: estudio de 31 pacientes. Med Clin 2004; 122: 748-52.

30. Jiménez-Alonso J, Martín-Armada M, Toribio M, Herranz-Marín MT, Rivera-Civico F, Pérez-Álvarez. F. Incidence of systemic lupus erythematosus among 255 patients with uveitis of unknown origin. Ann Rheum Dis 2002; 61: 471.

31. Pakrou N, Selva D, Leibovitch I. Wegener's granulomatosis: Ophthalmic manifestations and management. Semin Arthritis Rheum 2006; 35: 284-92.

32. Harper SL, Letko E, Samson CM, Zafirakis P, Sangwan V, Nquyen Q, et al. Wegener's granulomatosis: The relationship between ocular and systemic disease. J. Rheumatol 2001; 28: 1025-32.

33. Walton RC, Ashmore ED. Retinal vasculitis. Curr Opin Ophthalmol 2003; 14: 413-9.

34. Juillerat P, Mottet C, Froehlich F, Felley C, Vader JP, Burnand B, et al. Extraintestinal manifestations of Crohn's disease. Digestion 2005; 71: 31-6.

35. Bernstein $\mathrm{CN}$, Blanchard JF, Rawsthorne $\mathrm{P}, \mathrm{Yu}$ N. The prevalence of extraintestinal diseases in inflammatory bowel disease: A populationbased study. Am J Gastroenterol 2001; 96: 1116-22.

36. Mintz R, Feller ER, Bahr RL, Shah SA. Ocular manifestations of inflammatory bowel disease. Inflamm Bowel Dis 2004; 10: 135-9.

37. Chen L, Gordon LK. Ocular manifestations of multiple sclerosis. Curr Opin Ophthalmol 2005; 16: 315-20.

38. Smith JR, Rosenbaum JT. Neurological concomitants of uveitis. Br. J. Ophthalmol. 2004; 88: 1498-9.

39. Kadanoff R, Lipps B, Khanna A, Hou S. Tubulointerstitial Nephritis With Uveitis (TINU): A Syndrome Rheumatologists Should Recognize: A Case Report and Review of the Literature. J Clin Rheumatol 2004; 10: $25-27$.

40. Goda C, Kotake S, Ichiishi A, Namba K, Kitaichi N, Ohno S. Clinical features in tubulointerstitial nephritis and uveitis (TINU) syndrome. Am J Ophthalmol 2005; 140: 637-41.

41. Bachmeyer C, Turc Y, Curan D, Duval-Arnould M. Anterior uveitis as the initial sign of adult Kawasaki syndrome (mucocutaneous lymph node syndrome). Am J Ophthalmol 2000; 129: 101-2.

42. Smith LB, Newburger JW, Burns JC. Kawasaki syndrome and the eye. Pediatr Infect Dis J 1989; 116-8.

43. Rickman LS, Freeman WR, Green WR, Feldman ST, Sullivan J, Russack V, et al. Brief report: Uveitis caused by Tropheryma whippelii (Whipple's bacillus). N Engl J Med 1995; 332: 363-6.

44. Madu AA, Mayers M. Ocular manifestation of systemic infections. Curr Opin Ophthalmol 1995; 6: 88-91.

45. Edelsten C, Pearson A, Joynes E, Stanford MR, Graham EM. The ocular and systemic prognosis of patients presenting with sarcoid uveitis. Eye 1999; 13: 748-53.

46. Weisinger HS, Steinfort D, Zimmet AD, Hall AJ, Pesudovs K. Sarcoidosis: case report and review. Clin Exp Optom 2006; 89: 361-7.

47. Bloch-Michel E, Nussenblatt arb. International Uveitis Study Group recommendations for the evaluation of intraocular inflammatory disease. Am J Ophtahalmol 1987; 103: 234-5.

48. Jabs DA, Nussenblatt RB, Rosenbaum JT, The Standardization of uveitis Nomenclature (SUN) Working Group. Standardization of uveitis Nomenclature for Reporting Clinical Data. Results of the First International Workshop. Am J Ophthalmol 2005; 140; 509-16.

49. Rodríguez A, Calonge M, Pedroza-Seres M, Akova YA, Messmer EM, D'Amico DJ, et al. Referral patterns of uveitis in a tertiary eye care center. Arch Ophthalmol 1996; 114: 593-9.

50. Herranz Marín MT, Jiménez- Alonso J, Delgado Rodríguez M, Omar M, Rivero Cívico F, Martín Armada, et al. Clinical and biological markers of secondary uveitis: Results of a discriminant analysis. Med Clin 1997; 109: 786-91.

51. Gegúndez Fernández JA. Exploraciones complementarias en las uveítis. Arch Soc Esp Oftalmol 2003; 78; 12.

52. Font J, Cervera R, Ramos-Casal M, Espinosa G, Jiménez S, Ingelmo M. Diagnóstico y tratamiento de las enfermedades autoinmunes sistémicas. Guías Clínicas; 2006. p. 265-72.

53. Cervera R, Font J. Uveitis and systemic diseases. Med Clin (Barc). 1997; 109: 792-4.

54. Santaella RM, Fraunfelder FW. Ocular adverse effects associated with systemic medications: Recognition and management. Drugs 2007; 67: 75-93. 
55. Moorthy RS, Valluri S, Jampol LM. Drug-induced uveitis. Surv Ophthalmol 1998; 42: 557-70.

56. Cano Parra J, Díaz Llopis M. Drug induced uveitis. Arch Soc Esp Oftalmol 2005; 80: 137-49.

57. Asensio Sanchez VM, Botella Oltra G, Carrasco E. Biphosphonates and intraocular inflammation. Arch Soc Esp Oftalmol 2004; 79: 85-7.

58. Malik AR, Campbell SH, Toma NM. Bilateral acute anterior uveitis after alendronate. Br J Ophthalmol 2002; 86: 1443.

59. Shafran SD, Singer J, Zarowny DP, Deschenes J, Phillips P, Turgeon F et al. Determinants of rifabutin-associated uveitis in patients treated with rifabutin, clarithromycin, and ethambutol for Mycobacterium avium complex bacteremia: A multivariate analysis. Canadian HIV Trials Network Protocol 010 Study Group. J Infect Dis 1998; 177: 252-5.

60. Accorinti M, Pirraglia MP, Corradi R, Corsi C, Fabiani C, Pivetti-Pezzi P. Changing patterns of ocular manifestations in HIV seropositive patients treated with HAART. Eur J Ophthalmol 2006; 16: 728-32.

61. Bonfiolj AA, Orefice F. Toxoplasmosis. Semin Ophthalmol 2005; 20 : 129-41.

62. Marc L, Eric F. Viral uveitis. Arch Soc Esp Oftalmol 2000; 75: 261-80.

63. Dunn J. Review of immunosuppressive drug therapy in uveitis. Curr Opin Ophthalmol 2004; 15: 293-8

64. Okada A, Forrester V. Ocular inflammatory disease in the new millennium. Arch Ophthalmol 2000; 118: 116-9.

65. Michel SS, Ekong A, Baltatzis S, Foster CS. Multifocal choroiditis and panuveitis: Immunomodulatory therapy. Ophthalmol 2002; 109: 37883.

66. Ozdal PC, Ortac S, Taskintuna I, Firat E. Long-term therapy with low dose cyclosporin A in ocular Behcet's disease. Doc Ophthalmol 2002; 105: 301-12.

67. Murphy CC, Greiner K, Plskova J, Duncan L, Frost NA, Forrester JV, et al. Cyclosporine vs tacrolimus therapy for posterior and intermediate uveitis. Arch Ophthalmol 2005; 123: 634-41.

68. Hamuryudan V, Ozyazgan Y, Hizli N, Mat C, Yurdakul S, Tuzun Y, et al. Azathioprine in Behcet's syndrome: Effects on long-term prognosis. Arthritis Rheum 1997; 40: 769-74.

69. Touitou V, Escande C, Bodaghi B, Cassoux N, Wechsler B, Lemaitre C, et al. Diagnostic and the therapeutic management of Vogt-koyanagiHarada syndrome. J Fr Ophthalmol 2005; 28: 9-16.

70. Vianna RN, Ozdal PC, Deschenes J, Burnier MN Jr. Combination of azathioprine and corticosteroids in the treatment of serpiginous choroiditis. Can J Ophthalmol. 2006; 41: 183-9.

71. Siepmann K, Huber M, Stubiger N, Deuter C, Zierhut M. Mycophenolate mofetil is a highly effective and safe immunosuppressive agent for the treatment of uveitis A retrospective analysis of 106 patients. Arch Clin Exp Ophthalmol 2005; 15: 1-7.

72. Thorne JE, Jabs DA, Qazi FA, Nguyen QD, Kempen JH, Dunn JP. Mycophenolate mofetil therapy for inflammatory eye disease. Ophthalmology. 2005; 112: 1472-7.

73. Samson CM, Waheed N, Baltatzis S, Foster CS. Methotrexate therapy for chronic noninfectious uveitis: Analysis of a case series of 160 patients. Ophthalmol 2001; 108: 1134-9.

74. Durrani K, Papaliodis GN, Foster CS. Pulse IV cyclophosphamide in ocular inflammatory disease: Efficacy and short-term safety. Ophthalmology. 2004; 111: 960-5.

75. Benamour S, Naji T, Alaoui FZ, El-Kabli H, El-Aidouni S. Neurological involvement in Behcet's disease. 154 cases from a cohort of 925 patients and review of the literature. Rev Neurol (Paris) 2006; 162: 1084-90

76. Hale S, Lightman S. Anti-TNF therapies in the management of acute and chronic uveitis. Cytokine 2006; 33: 231-7.

77. Cobo-Ibáñez T, Muñoz-Fernández S, Hidalgo-Barrero V, Martín-Mola E. Medium-long term treatment with infliximab and methotrexate in posterior and/or chronic uveitis refractory to conventional treatment Med Clin (Barc) 2006; 126: 34-5.

78. Lindstedt E, Baarsma GS, Kuijpers RW, Hagen PM. Anti-TNF-alpha therapy for sight threatening uveitis. Br J Ophthalmol 2005; 89: 5336.

79. Wechsler B, Sable Fourtassou R, Bodaghi B, Huong DL, Cassoux N, Badelon I, et al. Infliximab in refractory uveitis due to Behcet's disease. Clin Exp Rheumatol 2004; 22 (4 Supl. 34): S14-6.

80. Tugal-Tutkun, Mudun A, Urgancioglu M, Kamali S, Kasapoglu E, Inanc M, et al. Efficacy of infliximab in the treatment of uveitis that is resistant to treatment with the combination of azathioprine, cyclosporine, and corticosteroids in Behcet's disease: An open-label trial. Arthritis Rheum 2005; 52: 2478-84.

81. Braun J, Baraliakos X, Listing J, Sieper J. Decreased incidence of anterior uveitis in patients with ankylosing spondylitis treated with the antitumor necrosis factor agents infliximab and etanercept. Arthritis Rheum 2005; 52: 2447-51.

82. Evereklioglu C. Current concepts in the etiology and treatment of Behcet disease. Surv Ophthalmol 2005; 50: 297-350.

83. Hernández Garfella ML, Díaz Llopis M, Salom Alonso D, Cervera Taulet E. Uveítis recurrentes y tratamiento con anticuerpos monoclonales (daclizumab). Arch Soc Esp Oftalmol 2004, 79: 598-604.

84. Papaliodis GN, Chu D, Foster CS. Treatment of ocular inflammatory disorders with daclizumab. Ophthalmol 2003; 110: 786-9. 